\title{
Mega Cisterna Magna in Ectrodactyly, Ectodermal Dysplasia and Cleft Lip/Palate Syndrome
}

Sir,

The combination of Ectrodactyly, Ectodermal dysplasia and Cleft lip with or without cleft palate is grouped together as EEC syndrome (OMIM No. 129900). The present report concerns an 11 month old male infant with EEC syndrome who additionally had an enlarged cisterna magna, detected on cranial magnetic resonance scan during routine dysmorphology evaluation, a finding that we describe for the first time in this syndrome. The infant was initially seen, for dysmorphology evaluation, at the outpatient department. He was born full term, through the vaginal route to non-consanguineous parents. There was no family history of congenital defects. The antenatal period of the mother and immediate post-natal period were uneventful. His weight and length were within the normal percentiles.

Examination revealed bilateral complete cleft lip and palate with protruding premaxilla and cleft lip nasal deformity. The teeth were absent. There was ectrodactyly of both feet. (Fig. 1) Superficial feature of ectodermal dysplasia included fine and sparse scalp hair. The assessment of the individual domains of the developmental milestones, revealed the following: gross motor- 9 month, fine motor- 9 month, cognition- 10 month, language- 8 month, social/emotional- 9 month, feeding-10 month. Clinical evaluation of the major systems was normal. Formal ophthalmological and auditory examinations were unyielding. The abdominal ultrasound and echocardiograph were normal. Cranial MR scan revealed diffuse cortical atrophy, vermian hypoplasia with mega cisterna magna. (Fig. 1) The cleft lip was operated 5 days later with banked forked flap.

Our child fulfilled the diagnostic criteria proposed by Buss et $a l^{1}$ which require the presence of ectodermal dysplasia of any variety and two of the following additional features: ectrodactyly, cleft lip/palate and lacrimal duct abnormalities.

Neurological abnormalities have been occasionally described in this condition. The most common manifestations include deafness and mental retardation. ${ }^{2}$ Instances of EEC syndrome with hypothalamo-pituitary insufficiency, manifested by varying degrees of hypogonadotrophic hypogonadism, growth hormone and prolactin deficiency with uniformly small pituitary gland on cranial imaging scans are reported. ${ }^{3,4}$ Ronconi et al ${ }^{5}$ reported neurogenic hypernatremia with adipsia and cerebral malformation (abnormal lateral ventricles,

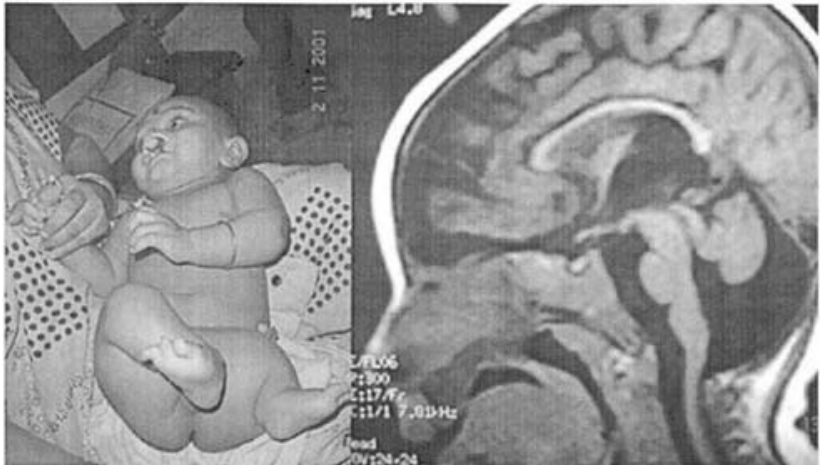

Fig. 1. Bilateral complete cleft lip and palate and ectrodactyly of feet (left panel) and sagittal cranial MR showing vermain hypoplasia in addition to cortical atrophy and mega cisterna magna (right panel).

agenesis of corpus callosum, calcified cortex) in a child with EEC syndrome. To our knowledge, ours is the first report to document posterior fossa abnormality in EEC syndrome.

\section{Rajoo Thapa, Debkrishna Mallick ${ }^{1}$, Biswajit Biswas $^{1}$ and Apurba Ghosh ${ }^{1}$ \\ Department of Pediatrics, Golisano Children's Hospital, Upstate Medical University, 750, E. Adams Street, Syracuse, New York 13210 USA and ${ }^{1}$ The Institute of Child Health, 11, Dr. Biresh Guha Street, Kolkata, West Bengal, India E-mail: rajoothapa@yahoo.co.in [DOI-10.1007/s12098-010-0072-7]}

\section{REFERENCES}

1. Buss PW, Hughes HE, Clarke A. Twenty four cases of the EEC syndrome: Clinical presentation and management. J Med Genet 1995; 32: 716-723.

2. Rodini ES, Richieri-Costa A. EEC syndrome: Report on 20 new patients, clinical and genetic considerations. Am J Med Genet 1990; 37: 42-53.

3. Van Maldergem L, Gillerot Y, Vamos E, Toppet M, Watillon $P$,Van Vliet G. Vasopressin and gonadotropin deficiency in a boy with the ectrodactylyectodermal dysplasia-clefting syndrome. Acta Pediatr Scand 1992; 81: 365-367.

4. Gershoni-Baruch R, Goldscher D, Hochberg Z. Ectrodactylyectodermal dysplasia clefting syndrome and hypothalamopituitary insufficiency. Am J Med Genet 1997; 20; 68: 168-172.

5. Ronconi GF, Ronconi M, Stella M, Soffiati G, Pesenti P. Neurogenic hypernatremia with adipsia and cerebral malformations in a child with ectrodactyly-ectodermal dysplasia-cleft lip-palate syndrome. Pediatr Med Chir 1985; 7: 893-897. 